\title{
Language Ethics: Linguo Psychology and Psycholinguistics (Analysis of the Language with Psychological Problems)
}

\author{
Valida Karimova \\ Division of Graduate Studies and Research, Khazar University, Baku, Azerbaijan
}

Email address:

kerimovavalide@yahoo.com

To cite this article:

Valida Karimova. Language Ethics: Linguo Psychology and Psycholinguistics (Analysis of the Language with Psychological Problems). Psychology and Behavioral Sciences. Vol. 6, No. 2, 2017, pp. 16-20. doi: 10.11648/j.pbs.20170602.11

Received: March 5, 2017; Accepted: March 23, 2017; Published: April 11, 2017

\begin{abstract}
The objective purpose of this research is to give brief and essential information about the school and directions of psycholinguistics, to investigate what psycholinguistics examine and define the search for an understanding of how humans develop, perceive and produce a language. Psycholinguistics is adjoining of psychology and linguistics. Being the research object of psycholinguistics speech is not only biological, but also a psychological factor and which characterized the person. Psycholinguistics explores the mental mechanisms of basic language processing (cognitive); how to comprehend words and intend them in the mind, how to understand a sentence, how to learn to read, how language and writing systems influence mental organizations. Language and comprehension perform the same functions. Language is a body which forms the idea. It is a great and complex system which maintains its value and deserves respect. Language is only the way with which learners make sense of the world expressed in a different language. Article gives an essential study which combines the fields of linguistics and psychology. Directly cover speech and language pathology, language psychology, language learning, language behavior or cognitive sciences.
\end{abstract}

Keywords: Purpose, Psycholinguistics, The Research Object, Psychology and Linguistics, Explores, Language, Speech and Language, Language and Mind

\section{Introduction}

As in every field of science, in linguistics also the nationality and humanity matters. As a result of this approach to the language, new fields of science occur. Those are: neurolinguistics, psycholinguistics, mathematical linguistics, computer linguistics, etc. Apart from this, the world linguists and Azerbaijani linguists held new studies and come to the interesting conclusions of, new words and appreciate this field of learning. At the time when linguistics leading structuralism is considered linguistic theory, in psychology behaviorism considered as a leading direction. In 1951 linguist and psychologists gathered together, combined their efforts and in America in Cornell University created linguistic and psychology Committee. However, after that no further efforts were made to work for working together, thus, linguist and psychologists still continue separately. In psycholinguistics the period of linguistics began its strong growth with period of N. Chomsky's Transformationgenerative Grammar on the basis of linguistic theory is not speech activities but should language competence. So, the main attention is focusing on understanding of language. [3]

During the last years, linguistics strengthened in Azerbaijan from its psychological aspect of investigation of language leaning to neurolinguistics, psycholinguistics and linguo-psychology. It must be depicted that, psycholinguistics and linguo-psychology (language of psychology) occur to the same object forward to the style from different approach. So that, the foundation of human speech and the new stage in state of mind is psycholinguistics. Moreover, its psychological approach is linguo-psychology. During the various historical periods in America, Europe, as well as in Russia famous scientists like Humboldt, Bloomfield, Chomsky and Shcherba worked in psycholinguistic field and put the foundation of the schools of world psycholinguistics. Moreover, the foundation of 
linguo-psychology as a school dates back to the Soviet period and associated with the name of famous Soviet linguists Vygotsky and Svetkova.

So, Psycholinguists who study adult processing are interested in how people understand and produce language. Psycholinguistic investigations focus on the constraints associated with real time processing. People understand language at the rate of about 300 words per minute, which implies that lexical retrieval, syntactic parsing, and semantic interpretation all occur in a matter of a few hundred milliseconds. Considering the size of the databases that must be consulted during comprehension, the speed and accuracy of human processing is truly astonishing.

\section{Previous Researches}

For many years, numerous researches and studies have been carried out in the field of linguo-psychology. Starting from the beginning of Greek linguistics, philosophers had different views about the origins of a language. In XVIII century in the works of J. J. Russo's "The experience of the language's formation, I. Herder's "The investigations regarding the origins of language" the origin of the language were coordinated with the human factor. So, in both works the reason of the language formation introduced by the human factors. [8]

The German philosopher Johann Herder, who was a French political and military hegemony of his time, (17441803) expressed the idea that a nation's language reflected the way its people thought according to the equation: one language $=$ one folk $=$ one nation. [7] The author compared our findings with the comments of the author above and suggests in an agreement with Johann Herder that language without humans and humans without language are impossible to survive. Language is dependent on humans, but cannot be equated to them. It's a dominant force and a leader over people and only processed by people.

... If it be true that we ... learn to think through words, and then language is what defines and delineates the whole of human knowledge ... In everyday life, it is clear that to think is almost nothing else but to speak. Every nation speaks ... according to the way it thinks and thinks according to the way it speaks... [11]

The formation of a language and learning its functions was ancient times attempts that have been made to the study and interpretation of the essence of language. Most attempts were based on classical logic. As the community, the science which created by itself, so the creation of language and its attitude to the role in human life gradually began to change. Now in the description of the nature and function of the language was referenced to the application of psychological principles. Language is a guide to "social reality"... Language is the only way with which learners make sense of the world expressed in a different language. Thus, psycholinguistics examines how we develop, perceive and produce language even though psycholinguistics is a mix of linguistics and psychology. This field (psycholinguistics) does not study "dead" languages. Because, in addition to ancient writings, the mental world of the community which causing the languages has not come. Psycholinguistics established approximately 50 years ago in USA. To the fields that learned psycholinguistics refers:

a. The emergence of speech. The stage character of the emergence of speech. The types of inner speech.

b. Perception of speech. The stage character of perception of speech. Understanding the text as a means of reflecting realities.

c. Language ability that acquired congenital. The initial conditions for the formation of language ability. The difference in the study of native and foreign languages.

d. Speech communication. Action, communication, intercourse and the ratio of language. The model of communication.

The process of speech is not only the biological, but also at the same time is psychological factor and which characterized the person. Definition and scope of psycholinguistics is shown in Figure 1. (See the Figure 1)

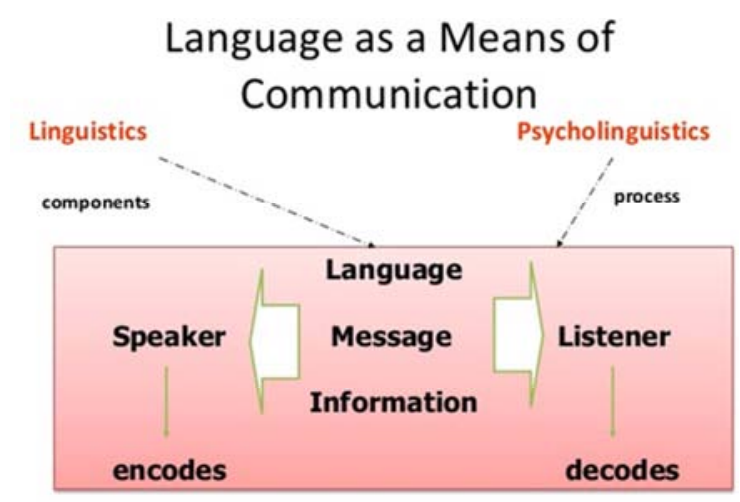

Figure 1. Definition and Scope of Psycholinguistics.

\subsection{Previous Research (L. Vygotsky)}

Really if behind the cognitive and thinking psychological processes stands language and speech, in that case as the primary criterion we need to take into account the language and speech which stands behind the cognitive and thinking psychological processes. All psychologists with a great confidence refer to L. Vygotsky: "Although part belongs to the whole, whole feature are not equal to the sum of the part's features." [8] About the views of Vygotsky the leading role of consciousness and thinking in a speech has one-sided approach. Really, Vygotsky observed the speech of a child's activity or as taken any work carrying out child's speech as his verbal reasoning. [18]

\subsection{Previous Research (J. Piaget)}

One of his reports J. Piaget stated that, in society every minute is born thousands of wild form of social existence. It is clear from the foregoing that, the human is biological, social, and biosocial being. As we can see, the human is extremely complex, in many cases contradictory, even 
struggle with itself. Therefore, the sciences which are learning human become 300 , it is not possible to complete a full thought about human.

\subsection{Conclusion}

As is known, the most common areas of psycholinguistics in America and Europe is "Behaviorism" and "Neobehaviorism". Psychological basis of the "Behaviorism" put forward by D. Uotson with "stimulus scheme", moreover, psychological basis of "Neobehaviorism" put forward by Morrison with its "stimulus-disposition-reaction".

\section{Discussion}

Recent years, in researches have been carried out the resolutions of psychological problems conditionally divided into 3 phases:

$1^{\text {st }}$ phase - the interim period until the date of officially announced the establishment of a science as psycholinguistics so, the period up to 1950 .

$2^{\text {nd }}$ phase - in America, East and West Europe (especially in Russia), Middle and Far East (especially in Japanese and China) the underlying establishment period of the psycholinguistic researches, during 1950-1970 years.

$3^{\text {rd }}$ phase - during last years in specific areas the psycholinguistic researches carried out. So that, 1980 and later periods. The book which was named "Psycholinguistics" was published in 1954. [19]

Philosopher, psychologist and known as linguist Alexander von Humboldt's works from the junction of linguistics and psychology conditionally possible to account the beginning or the foundation of psycholinguistics. According to the Humboldt "...language isn't a dead product, it should be considered as a creative process... in terms of the basic gist language not only stabile but also changeable... languagenot the product of action, it's even itself of action... language is always changing, language is mental activity which leads pronounced sounds to make a sense." [13] In the opinion of the writer's attitude, we suggest that language is more than communication; it's a social action and functions to express thoughts. In most cases, language is a dominant leader and ruler of the dependent. People are also dependent on it. Humboldt writes: "the language is a body which forms the idea." (Die Sprache ist das bildende Organ des Gedanken). An intellectual activity completely mental, deep inside and in a sense will disappear without a trace. Speech with the help of sound become matter and by the authorities feel is taken. For this reason, intellectual functioning and language are intertwined... From one side, speech is sound; from another side is a set of feeling impressions which aimed inside.

Humboldt considered that, in fact language has an ability to create a specific essence. This feature of language is the act of understanding a part. Moreover, essentially, language doesn't depend on comprehension and thinking. [ibid] Against the Humboldt consideration writer argues that, of course the first part of thought - "feature of language is the act of understanding a part", completely true consideration.
Moreover, the second part of this thought - "essentially language doesn't depend on comprehension and thinking", is not acceptable while have a great sympathy to the scientists. The author thinks that, the creation of language, also its practical use cannot be considered true; the creation of language or even the speech, is linked directly with the visual-verbal comprehension, as its communicative function. In complete contrast to Humboldt's this opinion, according to writer, the essence of a language or a speech which is pile of meaningless words, which is consisting sings chain, is just revealing the comprehension and the thinking processes.

In the history of linguistics N. Chomsky's "Transformative Psycholinguistics Theory" [9] is one of the analogical theories of that period. In "Transformative Psycholinguistics" from one side the development of formal language structure studied and use issues them, from another side the study of the meaning burden in the form of language. According this theory, the process of language learning is regarded as the mastering of grammatical structures and their formation rules.

Being the research object of psycholinguistics and during the mastery of speech, commenting on the mechanism of the process touches only psychological issues. Generally, cannot comment the linguistics issues. For this reason, "The theory of Speech activities to the analyses of the speech activities from not the linguistic position, but from the psychological position approach." [6]

During any kind of direction of linguistics such as: descriptive, functional, functional-semantic and structural analyses, discourse speech and in addition to the language's structural units of the linguistic features, its psychological features also should be considered. Language unit at the same time we call an element of reality presented by P. V. Chesnokov as a "means of language" and it was noted that as a result of the language's permanent and temporary activity emerge. Such facilities should be called language units. [5] So that, language unit first of all is an element of reality. Both in comprehension and the reality which reflected in the language, there is two image of intelligence. First, the element of reality which is in the objective arena; the second is the intelligence unit, which is equivalent to the image of language structure. [4] Language unit as an activated unit system, created via the human brain apparatus and activated unit system earn its distinction when combined with brain apparatus. The shape and speech which is beyond the human brain apparatus, is nothing - chain of meaningless noise or signs. By the way, the consideration said by the writer based on N. Chomsky's "Transformative Grammar" or "Cognitive roots".

\section{Findings}

The main factor contributing to the formation of structural units of language is the desire to provide or to learn information about the reality elements of surrounding, and one's own feelings and thoughts. The language is the product of brain activity and carries on psycholinguistics essence. [1] 
Language and comprehension are the facing mirrors which has an ability to reflect. [2]

Just starting to learn a language or the newly speaking children's language, from the respect of peculation differs from adults. In children, the language learning ability for a short period of time appears as a habit and inflammability. From the moment of birth, children in a passive communicate position. They has no any ability to answer, react, but hear the speech, words, intercourse of other persons in surroundings like parents, siblings, etc. The information (just starting to learn the language or the newly speaking children) which is given by author is from pediatricians and from different literatures. The aim of submission ideas just for a reminder and for creating a common thought as a part of research.

According to L. Vygotsky there is a dual relationship between environment and behavior. In the first case environment as an act, aimed addressing the behavior of an individual's duties. In the second case, acts as resource, means. [20]

The acceptance of speech happens in the first phase of comprehension. Moreover, the mastering of speech takes place with the image of intellect. Nowadays, the leading hypothesis which adopted by everybody is that among people only means of communication is a speech or a language. So, without the use of language units and word forms among people it is not yet possible meet the needs of exchange of information.

According to the teachings of V. Brukhin "Regarding the functions of language", P. Pazukhin believed that, "The reason or the language operation, generally its structure, as well as, being able to identify the essence of language the only function is being talkative." [12] Humboldt according the needs that forming the language says: “...language not only from the external need, public relations, need for communication, but formed for the inner, needs for humanity...", [10] and thus lays the foundation of language.

L. Vygotsky noted that, "communication necessarily is collection and implies on the improvement of meaning of the word. So, collection is possible during the development of communication." All our reference researches accepted that, the main function even one of the functions of language are communication.

It should be taken into consideration that, any shape or speech born as a result of brain activity. It gains its main real activity when combined with brain activities. Therefore, with determination we can say that, appeared speech is the result of created speech. When we say language, we mean it's all structural units and accepted it as a linguo-psychological category.

Language as the creation of its emerging appears from a chaotic manner. Language has both the form and content. The change of language to any direction is its direct improvement to progressive or regressive and depends on the reality elements of speech needs. Language implies specifically in a speech.

In modern age, it has begun a close contact between psychology and linguistics. We can see a clear manifestation of this in the formation of psycholinguistics. Psycholinguistics in a complex form which provides a field of science, study of psycholinguistics and linguistic behavior of complex speech as a field of science. Compared with the linguistics and speech psychology, psycholinguistics - has its own independent research subject. It is true that for a long time there is an area of psychology of speech. Psycholinguistics is a very young science. It appeared approximately at the end of $50^{\text {th }}$, at the beginning of $60^{\text {th }}$ years of XX century. The "father" of the Soviet psycholinguistic school was A. A. Leontiev. With the expansion of science different fields of psycholinguistics appeared. These are: general psycholinguistics, special psycholinguistics, social psycholinguistics, onto linguistics etc. we can list.

\section{Results}

This section presents the main result findings of the study. Researcher gives the clear and understandable essence of her study to the readers. In order to give the objective purpose of the research she tried to cover the theoretical issues of psycholinguistics, comment on disputable moments, tried to clarify the comprehension and thinking mechanism.

One interesting point is that, psycholinguistics and linguopsychology (language's psychology) come forward to the same object from different approach. Thus, the formation of human's speech, in psycholinguistics from the linguistic point, in linguo-psychology approaches from the psychological point of view this article concludes that, with the analysis of linguistic and psychological point of language's structure, its linguo-psychological essence, chaotic system understanding and development tendency of language explained. The main function of language is communication. Language specifically exists in speech, from historical perspective language and its structural units just appear with comprehension and thinking processes.

As a result of this study, the object of the linguopsychology is generation, perception and notion of the structural units of language and speech, and also learning first and second languages fields.

\section{Conclusion}

And yet, the author concluded that, language and comprehension is the same type system that two mirrors are facing similar. Things perceived in language system and the things which are in the system of language reflected in comprehension system. Moreover, among them we will not put full equality sign. Thus, everything in language system without exception is reflected in comprehension system.

Perhaps the closest partnership in cognitive science is the one between psycholinguistics and formal linguistics. The two disciplines were born together and have grown up essentially side-by-side as sister disciplines. But like many family relationships, the dynamics between these fields have 
been complicated. At present, psycholinguistics and formal linguistics are not nearly as close as they once were, and it appears that scholars from both fields have decided they can do their work better independently rather than cooperatively. Finally, the study of language should be at the core of human cognitive science. Moreover, because we now have ways of looking at human brains when they perform tasks without causing people any pain or harm, it is now possible to develop a biologically plausible model of language. Linguists should join this enterprise; it is a lot of fun, and results have been impressive.

\section{References}

[1] Askerov. M. B. The Psycholinguistic Essence of Language. "Researchs". ANAS Institute of Linguistics. Baku, "Science", 2004, № 2, pp. 60-64.

[2] Askerov. M. B. Mutual Reflections in Language and Perceive. "Scientific Researchs", ANAS, XXV edition, Baku, "Echo", 2006, pp. 111-115.

[3] Askerov. M. B. Theory of Linguo psychology Unity. Baku, 2005. (Osgərov. M. B. Linqvo-psixoloji Vəhdət Nəzəriyyəsi. Bak1, 2005)

[4] Chesnokov. P. V. Basic Units of Language and Thinking. Rostov. 1966, pp. 91.

[5] Chomsky. N. Aspects of the Theory of Syntax. M., 1972, pp. 13.

[6] Chomsky. N. Syntactic Structures. New in Linguistics, M., 1962. $2^{\text {nd }}$ edition.

[7] Davies. A and Elder. C, Claire Kramsch. 2008 - Language, Thought and Culture and the problem of Linguistic Relativity. Chapter 9, part 9.2.1. pp236.

[8] Gurbanov. A. General Linguistics. Baku, Education. 1989, pp. 54.
[9] Humboldt. V. Selected Works on Linguistics, M., 1984, pp. 69-70.

[10] Humboldt. V. O. On the difference between the organisms of a human language and the influence of this difference on the mental development of the human race. 1859, pp. 47.

[11] I. Herder. 1772. 1960, pp. 99-100.

[12] Pazukhin. R. V. K. Bühler's theory of the functions of language as an attempt at a psychological solution of linguistic problems. №2, M. 1963, pp. 90-110.

[13] Psycholinguistics. A Survey of Theory and Research Problems. Ed. By Ch. E. Osgood and T. A. Sebeok. Baltimore, 1954.

[14] Veysalli. F. Y. Introduction to Linguistics. Baku, 2013.

[15] Veysalli. F. Y. Introduction to Germanic Linguistics. Baku, 2011.

[16] Veysalli. F. Y. Language. Baku, 2007.

[17] Veysalli. F. Y. Basics of Structural Linguistics. Baku, 2008.

[18] Vygotsky. L. S. Psychology. April Publishing, "Eksmo Press", Moscow, 2000, pp. 267.

[19] Vygotsky. L. S. Psychology. April Publishing, "Eksmo Press", Moscow, 2000, pp. 840-842.

[20] Vygotsky. L. S. Instrumental Method in Psychology. Moscow, 1960, pp. 227.

[21] Wurm, L. H., \& Ross, S. E. Conditional root uniqueness points: Psychological validity and perceptual consequences. 2001.

[22] Zorzi, M. Serial processing in reading aloud: No challenge for a parallel model. Journal of Experimental Psychology: Human Perception and Performance, 26, 2000, pp. 847-856.

[23] Zwitserlood, P., Boelte, J., \& Dohmes, P. Morphological effects on speech production: Evidence from picture naming. Language and Cognitive Processes, 15, 2000, pp. 563-591. 